\title{
ANTROPOLOGIAS MUNDIAIS \\ Para um novo cenário global na antropologia
}

\section{Gustavo Lins Ribeiro}

\section{Cosmopolíticas}

Entendo as questões tratadas pelos antropólogos, suas preocupações teóricas, contribuições para o conhecimento, dilemas e erros, assim como as capacidades heurísticas e epistemológicas da disciplina, como inseridos em dinâmicas sociais, culturais e políticas que se desdobram em contextos historicamente estruturados, de diferentes maneiras, por relações de poder variáveis. As principais forças sociológicas e históricas que

* Este texto foi apresentado como uma conferência no seminário internacional "A donde va la antropología?", em setembro de 2004, em comemoração aos trinta anos da Universidad Autónoma Metropolitana - Iztapalapa, Cidade do México.

(continua na página 164)

Artigo recebido em novembro/2005

Aprovado em dezembro/2005 atravessam o campo político e epistemológico da antropologia são conectadas às dinâmicas do sistema mundial e àquelas dos Estados-nações, principalmente às que dizem respeito aos diversos papéis que os "outros" ou a "alteridade" podem ter em cenários internacionais e nacionais.

Este artigo é fortemente inspirado em um movimento coletivo chamado Redes de Antropologias Mundiais (RAM) do qual sou membro (ver site www.ram-wan.org). A rede tem como objetivo pluralizar as visões prevalecentes da antropologia em uma conjuntura onde persiste a hegemonia dos discursos anglo-saxões sobre a diferença. Essa perspectiva provém da compreensão de que, em uma época de globalização exacerbada, os antropólogos não têm discutido consistentemente a natureza corrente de sua prática e das transformações que ela atravessa em escala global. Isso pode ser uma conseqüência da hegemonia internacional da antropologia norte-americana e sua tendência a confundir suas próprias crises internas com uma global. 
A rede de "antropologias mundiais" pretende contribuir para a articulação de uma antropologia diversificada mais consciente das condições sociais, epistemológicas e políticas de sua própria produção. A rede tem três objetivos principais: a) examinar criticamente a disseminação internacional da antropologia - como uma série de discursos e práticas ocidentais variáveis - dentro e através de campos de poder nacionais, assim como os processos mediante os quais essa disseminação acontece; b) contribuir para o desenvolvimento de paisagens plurais de antropologias que sejam menos formadas pelas hegemonias metropolitanas e mais abertas ao potencial heteroglóssico da globalização; e c) encorajar conversas entre antropólogos de diversas regiões do mundo a fim de avaliar a diversidade das relações entre antropologias regionais e nacionais e um discurso disciplinar, contestado, atravessado por relações de poder. ${ }^{1}$ Este projeto faz parte de uma antropologia crítica da antropologia, uma perspectiva que descentraliza, re-historiciza e pluraliza o que tem sido considerado "antropologia" até então. Ele questiona não só os conteúdos, mas também os termos e as condições dos encontros antropológicos. "Antropologias Mundiais" têm como objetivo a construção de um cânone policêntrico, que, de forma parecida ao multiculturalismo policêntrico (Shohat e Stam, apud Turner, 1994), implica em uma reconceitualização das relações entre comunidades antropológicas. A antropologia hegemônica monológica precisa ser substituída por antropologias heteroglóssicas. Como indicou Bakhtin (Werbner, 1997, p. 6), a heteroglossia "enfraquece a autoridade do costume e da tradição reificados".

Uma outra observação introdutória refere-se ao meu entendimento da antropologia como uma cosmopolítica. A noção de cosmopolítica procura prover uma perspectiva crítica e plural sobre as possibilidades de articulações supra e transnacionais. Ela é baseada, por um lado, nas evocações positivas associadas historicamente à noção de cosmopolitismo e, por outro, em análises nas quais assimetrias de poder são de fundamental importância. ${ }^{2}$ Cosmopolítica abrange discursos e modos de fazer política que se preocupam com seus alcances e impactos globais. Interessam-me, sobretudo, as cosmopolíticas relacionadas a conflitos sobre o papel da diferença e da diversidade na construção de grandes unidades políticas. Entendo a antropologia como uma cosmopolítica concernente às estruturas de alteridade (Krotz, 1997), uma cosmopolítica que pretende ser universal, mas que, ao mesmo tempo, é altamente sensível a suas próprias limitações e à eficácia de outras cosmopolíticas. Poderíamos dizer que antropologia é um discurso político cosmopolita relativo à importância da diversidade para a humanidade. ${ }^{3}$

Entender a antropologia como uma cosmopolítica não é um ato destituído de implicações. Significa, desde o princípio, que a antropologia não é o único discurso que trata da importância da diversidade, apesar de sua sofisticação. De fato, deveríamos esperar que a antropologia fosse uma das mais sofisticadas cosmopolíticas sobre diversidade, uma vez que é uma disciplina acadêmica. Mas, um discurso xamanístico de um ianomami na Amazônia brasileira pode também representar uma cosmopolítica, e isso realmente ocorre. Basta ver a intertextualidade cultural presente nas falas do líder ianomami Davi Kopenawa, que articula discursos xamanísticos com ambientais globais relativos ao destino da Terra (Albert, 1995). Olhar para a antropologia como uma cosmopolítica também significa que a posição da disciplina no mercado intelectual/acadêmico não precisa restringirse ao "escaninho selvagem" como colocado por Michel-Rolph Trouillot (1991). A variedade cada vez maior de alteridades criadas pelos processos de globalização tem, há algum tempo, trazido vários tópicos diferentes para os antropólogos.

Outra implicação importante de ver a antropologia como uma cosmopolítica é a compreensão de que a história da antropologia acadêmica do Atlântico Norte não é suficiente para dar conta da história do conhecimento antropológico em escala global. ${ }^{4}$ Isso decorre não apenas das especificidades das histórias das antropologias em cenários nacionais diferentes, mas também do fato de que outras cosmopolíticas se desenvolveram em outras regiões do mundo e configuraram uma variedade de conhecimentos parecidos com o que depois seria conhecido como antropologia, a "disciplina acadêmica que teve seu primeiro aparecimento na região do Atlântico Norte" (Danda, 1995, p. 23). Antropólogos mexicanos, por exemplo, normalmente localizam o começo 
da "antropologia" mexicana no século XVI e se referem especialmente aos escritos de monges, como Bernardino de Sahagún, como o momento fundador do pensamento antropológico naquele país (Lomnitz, 2002, p. 132). Ajit K. Danda considera corretamente que é necessário distinguir entre antropologia como "disciplina acadêmica" e antropologia como "corpo de conhecimento". O autor afirma que "parece ser uma noção equivocada supor que no resto do mundo não se encontrava conhecimento antropológico e que, até um ímpeto da região norte-atlântica se espalhar por outras partes, não haveria nenhum exercício significativo digno de referência que viesse daquelas áreas" (1995, p. 23). Ele exemplifica com a literatura indiana antiga, voltando no tempo até o ano de 1350 a.C. quando a Manava Dharmashastra (A Sagrada Ciência do Homem) foi escrita.

Em suma, a antropologia é uma cosmopolítica ocidental que se consolidou como disciplina acadêmica formal no século XX, internamente a um sistema universitário ocidental cada vez maior e em expansão mundo afora. Como outras cosmopolíticas, a antropologia reflete a dinâmica histórica do sistema mundial, principalmente aquelas relacionadas às estruturas de alteridades. ${ }^{5}$ Algumas das mudanças mais fundamentais na antropologia do século XX foram decorrentes das mudanças na condição de sujeito do "objeto" antropológico por excelência: povos nativos ao redor do planeta.

\section{Transformações em sistemas de poder}

Para melhor entender essa antropologia crítica da antropologia, devo apresentar como vejo a trajetória da antropologia no século XX. Não pretendo fazer um resumo da história da disciplina com suas muitas realizações e problemáticas. Prefiro enfocar como ela se enredou com geopolíticas e poderes nacionais/globais. Meus argumentos giram em torno de transformações que ocorreram principalmente nas antropologias hegemônicas. Trata-se de formações discursivas e práticas institucionais típicas da normalização da antropologia em modalidades acadêmicas, principalmente nos Estados Unidos, na Grã-Bretanha e na França (Restrepo e Escobar, 2005). Antropologias anglo-saxãs, sobretudo a norte-americana, representam cenários interessantes para ver as intersecções entre sistemas de poder nacionais e mundiais. Quero mostrar, ao final desta seção, que, atualmente, há novos agentes em ação, gerando uma situação que abre desafios e perspectivas inesperadas. Tal agência não é composta por líderes de povos indígenas transformados pela modernização, nem por migrantes "exóticos" em cidades globais, forças importantes para a problematização das antropologias hegemônicas. Alcida Ramos (2004), por exemplo, mostra que chegou a hora dos índios fazerem suas próprias antropologias sobre seus próprios mundos. Eu adicionaria que etnografias indígenas sobre nossos próprios mundos também dariam um inesperado ímpeto à nossa disciplina. Mas o que quero enfatizar é que hoje também existe uma nova força advinda de dentro da própria antropologia. Refiro-me ao papel cada vez mais importante que as antropologias nãohegemônicas têm na produção e na disseminação de conhecimento em escala global.

As primeiras décadas do século XX, até a Segunda Guerra Mundial, foram momentos de consolidação e expansão da antropologia em muitos países. Instituições foram fundadas e redes internacionais criadas, replicando relações geopolíticas existentes entre diferentes lugares do sistema mundial, em um período em que impérios e Estados-nações estavam firmemente estabelecidos. Foi um momento de fundação e triunfal. A antropologia começou a ser uma disciplina com um perfil próprio, a ter um número cada vez maior de instituições dedicadas ao seu crescimento e reprodução, assim como uma massa visivelmente crescente de praticantes. Além das antropologias hegemônicas norte-americana, britânica e francesa, várias outras começaram a expandir em lugares como Japão, México e Rússia. A educação de grandes figuras fundadoras de diversas "antropologias nacionais" em centros anglosaxões e o intercâmbio internacional proveram, com freqüencia, uma base para cooperação e disseminação de conhecimento antropológico, criando um sentido de compartilhar um mesmo campo de objetivos de pesquisa e programas disciplinares. Uma vez que fazer antropologia e viajar sempre estiveram associados, desde os primeiros momentos da disciplina muitos antropólogos estabeleceram redes e estruturas transnacionais. 
As histórias das antropologias mexicana e japonesa ilustram bem como a expansão desse período caracterizou-se pelo relacionamento que os antropólogos tinham com processos de construção da nação e de construção de impérios. Após a revolução mexicana, a necessidade de integrar índios/camponeses ao Estado-nação foi a principal força por trás do crescimento de uma antropología indigenista, com o apoio de poderosas instituições estatais (Krotz, 2006). ${ }^{6}$ Inicialmente preocupados com as origens da cultura japonesa, antropólogos daquele país logo passaram a seguir a expansão colonial do seu Estado-nação e a fazer pesquisa de campo em países tais como Coréia e China, onde o poder imperial japonês era exercido (Yamashita, 2006). Em suma, nas primeiras décadas do século XX, com diferentes nacionalismos e colonialismos operando, os "nativos" eram vistos principalmente por uma perspectiva moderna como povos que precisavam ser conhecidos a fim de propiciar sua integração ao Estado-nação ou a impérios.?

A Segunda Guerra Mundial, um momento fundamental de rearranjo do sistema mundial, mudaria radicalmente esse panorama. Foi uma inflexão do período anterior de expansão global da disciplina, um momento de redefinição da relação entre a antropologia e o Estado-nação, que causou impacto nas gerações posteriores. Se, em muitas situações - a Grã-Bretanha é o caso mais visível -, as relações da antropologia com interesses estatais aconteceram sob o guardachuva da administração colonial, naquele momento a guerra invadia o próprio núcleo da disciplina de forma bem mais intensa e completa do que durante a Primeira Guerra Mundial. Antropólogos norte-americanos tinham se envolvido até certo ponto com esforços de inteligência durante a Primeira Guerra, um conflito que, ao contrário da Segunda, não gerou consenso amplo entre os intelectuais norte-americanos. Muitos deles defenderam uma posição neutra. De acordo com Marcio Goldman e Federico Neiburg,

[...] no campo da antropologia, as discordâncias chegaram a um ponto culminante quando, logo após a Guerra, durante sua reunião anual de 1919, um voto de censura removeu Franz Boas da presidência da Associação Americana de Antropologia. Apesar do fato da razão explícita ter sido a denún- cia pública da participação de antropólogos em agências federais de inteligência e espionagem, na realidade a AAA estava também censurando Boas pelas suas posições pacifistas contra a intervenção americana na Primeira Guerra Mundial. Como Stocking observou, o clima de patriotismo exacerbado após 1918 não podia tolerar idéias pacifistas formuladas por um autor que era visto por alguns como um suspeito imigrante alemão de origem judaica (2002, p. 188).

Algumas décadas depois, Boas consideraria abandonar sua carreira como antropólogo para combater o nazismo (Idem, pp. 194-195), fato que pode ser tomado como um índice do clima consensual associado à Segunda Guerra Mundial. Vários de seus ex-alunos, tais como Margaret Mead, lideraram a participação da antropologia no esforço bélico. Em alguns casos, os nativos tornaram-se inimigos, tal como em O crisântemo e a espada, escrito por Ruth Benedict, em 1942, para o Departamento de Informação da Guerra, e publicado em 1946. Este livro é, talvez, o mais famoso exemplo de associação entre conhecimento antropológico e esforço bélico. A Segunda Guerra Mundial, com unanimidade sem precedente, provou que a antropologia poderia ser útil para prover "inteligência" sobre o inimigo, no sentido de ser capaz de superá-lo; sobre os aliados, para aprender como cooperar com eles; e sobre a própria nação, para aprender como usar sua própria força (Idem, pp. 198-199). As relações espúrias entre pesquisa antropológica e interesses de Estado tiveram um exemplo mais concreto na participação de vários antropólogos na administração de campos de concentração de japonesesamericanos durante a Segunda Guerra Mundial (Suzuki, 1981). Ainda se faz necessária uma história consistente do papel da antropologia durante a Segunda Guerra Mundial em diferentes países. ${ }^{8}$ Esse foi um período importante porque revelou cruamente modos de interação entre a antropologia e as elites estatais, que certamente seriam mais improváveis em períodos de paz.

A Segunda Guerra Mundial foi um ponto decisivo na história do sistema mundial. Entre outras coisas, representou a exaustão da era imperialista-colonialista clássica e o começo de um novo momento sob a hegemonia dos Estados 
Unidos. Ideologias colonialistas de expansão foram substituídas pelas desenvolvimentistas (Escobar, 1995). Logo, a Guerra Fria criaria um mundo dividido em duas metades antagônicas, uma divisão que teve fortes impactos no desenvolvimento de antropologias em países como a China e a União Soviética (Smart, 2006; Vakhtin, 2006). O verdadeiro período triunfante e de expansão rápida da antropologia começou após a Segunda Guerra Mundial. Em parte, coincidiu com a força modernizadora da época que demandava massas instruídas, pessoas com maior acesso a um sistema universitário que crescia rapidamente em muitos países. Mas a rápida expansão da antropologia também coincidiu com uma renovada demanda por conhecimento "científico" sobre nativos estranhos e exóticos no interesse das necessidades mundiais de "desenvolvimento". Cada vez mais, os nativos deixavam de ser súditos coloniais de impérios ocidentais para se tornarem cidadãos de Estados-nações "subdesenvolvidos". Desigualdades e diferenças dentro do sistema mundial deveriam então ser gerenciadas por meios pacíficos e racionais, tais como ideologias e planos de desenvolvimento sustentados por agências multilaterais como as Nações Unidas e o Banco Mundial.

Em um período cheio de confiança na força da modernização e no papel da ciência e da tecnologia no grande destino da humanidade, $\mathrm{O}$ número de praticantes de antropologia aumentou firmemente. Mais de cinqüenta anos atrás, Alfred Kroeber (1953) fez um survey sobre a antropologia mundial e publicou os achados no seu famoso livro Anthropology today. Ele chegou a um número de 2 mil antropólogos em todo o mundo, seiscentos deles membros da Associação Americana de Antropologia (AAA). Hoje, esta associação tem cerca de 11 mil membros. Por outro lado, outras comunidades antropológicas cresceram e se diversificaram desde a Segunda Guerra Mundial. Quando a Associação de Antropólogos Sociais do Reino Unido e da Commomwealth (ASA) foi fundada em 1946, tinha aproximadamente vinte membros. Ela cresceu, atingindo mais de 150 membros, em 1962, e cerca de 240, em 1968 (Asad, 1973). Hoje a ASA tem seiscentos membros. No que diz respeito ao Brasil, Otávio Velho (1980) aponta que 41 pessoas freqüentaram o primeiro encontro brasileiro de antropologia, em 1953, 109, em 1959, 141, em 1968, e 408, em 1979. Em 2004, mais de 1.500 pessoas freqüentaram o encontro brasileiro (o Gráfico 1 mostra o número aproximado de sócios de algumas das maiores associações antropológicas em 2004).

\section{Gráfico 1* \\ Números de Associados de Algumas das Maiores Associações (2004)}

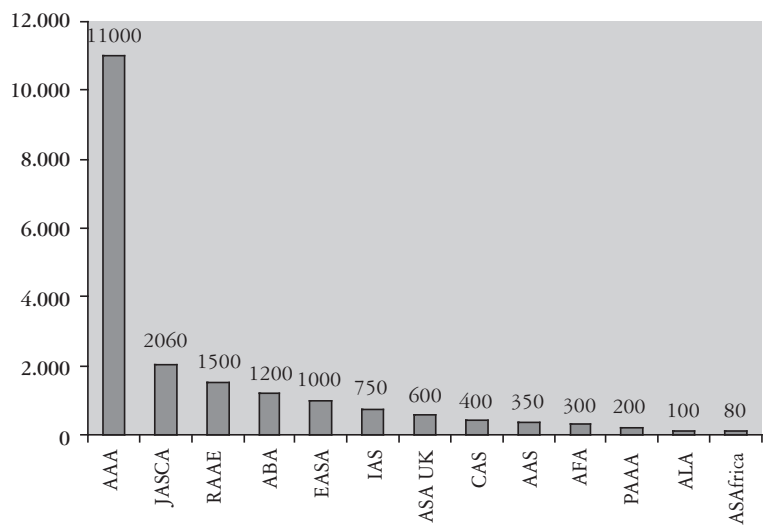

*Baseado em survey conduzido durante o encontro "Antropologias Mundiais: Fortalecendo a Organização Internacional e a Eficiência da Profissão”, junho de 2004, Recife, com a presença de catorze presidentes de associações antropológicas (AAA, Associação Americana de Antropologia; JASCA, Sociedade Japonesa de Antropologia Cultural; RAAE, Associação Russa de Antropólogos e Etnólogos; ABA, Associação Brasileira de Antropologia; EASA, Associação Européia de Antropologia Social; IAS, Sociedade Antropológica Indiana; ASA, Associação dos Antropólogos Sociais do Reino Unido e da Commonwealth; CAS, Sociedade Canadense de Antropologia; AAS, Sociedade Antropológica Australiana; AFA, Associação Francesa de Antropologia; PAAA, Associação Antropológica Pan-Africana; ALA, Associação Antropológica Latino-Americana; ASA, Antropologia Sul Africana).

Mas processos políticos do período pósguerra logo convergiriam, na década de 1960, a uma grande crise de representação da antropologia hegemônica causada por uma mudança clara 
na posição de sujeito do nativo e/ou de grupos vulneráveis, o "objeto" de pesquisa clássico da antropologia. A descolonização teve impactos sobre a antropologia britânica que ainda hoje estão sendo digeridos, ao passo que o Movimento por Direitos Civis e a mobilização contra a Guerra do Vietnam mudaram o cenário norte-americano. Os nativos reagiram falando com suas próprias vozes e criticaram a antropologia por ser um instrumento do colonialismo, principalmente na África, onde a última onda de descolonização estava acontecendo e o papel da disciplina durante tempos coloniais foi problemático (Nkwi, 2006). Afroamericanos forçaram o Estado-nação estadunidense a um novo pacto nacional, em que cultura e identidade se tornaram altamente politizados, em um movimento que abriria o caminho para o multiculturalismo e as políticas da diferença. A guerra imperialista no Vietnam mobilizou corações e mentes contra a geopolítica e o nacionalismo simplistas e ferozes dos militantes da Guerra Fria. A "era da inocência" da antropologia (Wolf, [1969] 1974) acabou, ao passo que a relação entre conhecimento e poder tornou-se mais explícita com o envolvimento de antropólogos em atividades de inteligência contra-insurgenciais, na Tailândia, por exemplo, levantando novos problemas éticos e políticos (Wolf e Jorgensen, 1975). ${ }^{9}$ Todos aqueles outros exóticos e subalternizados precisavam ser vistos como sujeitos de seus próprios destinos. A crítica da antropologia tornou-se uma "literatura de angústia" (Ben-Ari, 1999), aprofundando uma das auto-representações mais fortes da antropologia (Wolf e Jorgensen, 1975), segundo a qual se trata de uma disciplina que é filha do imperialismo ocidental (Gough, 1975), da violência, como disse Lévi-Strauss (1966), ou se trata de uma disciplina revolucionária que questiona uma suposta superioridade do Ocidente (Diamond 1964). BenAri (1999) vê essa ambivalência como uma dicotomia que permeia a antropologia desde o final do século XIX, resumindo-a da seguinte maneira: a antropologia ou é co-responsável pelos problemas criados pela expansão ocidental, ou é um instrumento para um melhor entendimento humano. ${ }^{10}$

Este tipo de crítica foi articulado nas décadas de 1960 e 1970, principalmente por uma abordagem de economia política marxista e, em geral, em nome das lutas do Terceiro Mundo contra o colonialismo e o imperialismo. Os volumes, Reinventing anthropology ([1969] 1974), de Dell Hymes, Anthropology and the colonial encounter (1973), de Talal Asad, assim como Anthropologie et impérialisme (1975), de Jean Copans, representam as melhores ilustrações dessa literatura. Mesmo que as contribuições dessas obras tenham sido desenvolvidas desigualmente e tenham ênfases diferentes, elas compartilharam a insistência na necessidade de uma mudança nas fundações epistemológicas, institucionais e políticas da antropologia anglo-americana.

O sistema mundial passou por outra rodada de transformações com os eventos que levaram ao fim da União Soviética (1989-1991), terminando o período da Guerra Fria e inaugurando o atual momento que pode ser chamado de "era da globalização realmente existente". Um capitalismo triunfante perdeu sua contraparte, tornou-se cada vez mais transnacionalizado e estendeu sua capilaridade a territórios e mercados anteriormente fechados. A globalização realmente existente criou fluxos cada vez mais complexos de mercadorias, pessoas e informação, redefinindo as relações entre espaços globais fragmentados - o local e o global. A compressão do tempo-espaço (Harvey, 1989) ganhou impulso adicional com novos avanços das indústrias de comunicação sob a hegemonia do capitalismo informacional e eletrônico. Tecnologias digitais e a internet instalaram o que Castells (1996) chama de modo informacional de desenvolvimento. O ciberespaço propiciou um aumento enorme do intercâmbio global de informação e a emergência de uma comunidade transnacional imaginada-virtual (Ribeiro, 1998), o meio estratégico de criação e apoio de uma sociedade civil global cada vez mais presente. Novas migrações internacionais criaram segmentações étnicas mais diversificadas dentro dos Estados-nações em quase todos os lugares, redefinindo o papel da distância na definição de sujeitos etnográficos. Para antropólogos hegemônicos, nativos deixaram de ser aqueles povos exóticos vivendo a milhares de quilômetros de suas casas; eles tornaram-se vizinhos.

Todas essas transformações geraram outra crise de representação da antropologia hegemônica. As linhas entre nativos e não-nativos estavam embaçadas, as estruturas de alteridades 
socioculturais (Krotz, 1997) aumentaram em complexidade em contextos globais e nacionais. Entraram em cena outras disciplinas, como os estudos culturais, e abordagens teóricas, como o pós-colonialismo, que não carregavam o pecado original da antropologia de cooperação com o colonialismo. A globalização reforçou as contradições entre segmentos étnicos e o poder do Estado-nação. Multiculturalismo e políticas da diferença foram internacionalizados, reforçando, assim, movimentos políticos "nativos" e a culturalização da política.

As duas principais crises da antropologia supracitadas estavam intimamente relacionadas às posições variantes, internamente a estruturas de poder, dos sujeitos clássicos da pesquisa antropológica - grupos nativos ou sem poder -; estavam relacionadas a mudanças do relacionamento da antropologia com o "escaninho do selvagem" (Trouillot, 1991). Mas hoje há outro elemento que não foi devidamente incorporado por críticas anteriores e que com certeza impactará a antropologia, a saber, a presença internacional das antropologias não-hegemônicas e sua importância na produção e na reprodução de conhecimento. Isso não é realmente uma novidade, já que o cenário acadêmico e científico - e a antropologia é uma confirmação dessa afirmação - tem sido sempre propenso à internacionalização. Entretanto, com o crescimento do número de antropólogos fora dos países hegemônicos chegamos a uma situação distinta. Apesar disso, a fertilização cruzada internacional tem acontecido dentro de um universo muito limitado, composto de um número restrito de parcerias. É verdade que em locais como o sistema universitário norte-americano a diversidade das nacionalidades do corpo docente e dos pesquisadores aumentou nas últimas décadas, um resultado do próprio lugar central dos sistemas científicos, tecnológicos e acadêmicos norte-americanos no mundo globalizado. Mas esse aumento em diversidade, na antropologia e em outras disciplinas, não tem correspondido a um crescimento intenso no consumo de uma produção estrangeira diversificada, fato que indica a normalização do trabalho daqueles a quem Aijaz Ahmad (1994) chamou de "intelectuais étnicos". Na verdade, não estou tão preocupado com a migração de pessoas e com a contribuição que muitos estudiosos estrangeiros têm feito historicamente ao poder dos centros hegemônicos. Minha principal preocupação é com o que pode ser chamado de migração de textos, conceitos e teorias.

A monotonia da fertilização cruzada internacional não é um problema exclusivo da antropologia. O sociolingüista Rainer Enrique Hamel, no seu estudo Language empires, linguistic imperialism, and the future of global languages, considerou que "pode ser tomado como sintoma do imperialismo científico do inglês o fato de que [...] a maioria de autores de países de língua inglesa e suas antigas colônias que escreve sobre o mundo como um todo, o faz sem citar um único texto de língua não-inglesa em suas vastas bibliografias" (2003, p. 20). Esse problema, entretanto, é particularmente interessante quando percebido em uma disciplina que preza a diversidade tão intensamente. A polifonia na produção antropológica deve significar, primeiro, o reconhecimento de uma enorme produção em diferentes locais do sistema mundial, produção que precisa ganhar visibilidade se é que vamos levar a sério o papel da diversidade na construção de discursos mais densos e na complexificação da fertilização cruzada. Além disso, deve significar uma compreensão das trocas desiguais de informação que ocorrem dentro do sistema mundial de produção intelectual e a conseqüente tomada de posições políticas que pretendam ir além da situação presente em direção a um ambiente mais igualitário e, assim, mais enriquecedor. Finalmente, também deve significar uma crítica intelectual e a ação crítica subseqüente sobre os mecanismos que sustentam tais trocas desiguais não só dentro do cenário acadêmico, mas também fora dele, envolvendo outras formas de produção de conhecimento, outras cosmopolíticas sobre alteridades.

O presente é mais um momento de reinvenção da antropologia. Desta vez, a mudança não será provocada por outra crise na posição de sujeito das populações nativas - a disciplina já passou por essa experiência -, mas por mudanças nas relações entre antropólogos localizados em diferentes locais do sistema mundial. Steban Krotz também antevê profundas transformações nessa direção. Para ele,

[...] apesar de os principais impulsos da produção de conhecimento antropológico continuarem 
vindo de países onde essa ciência se originou, tais impulsos estão também acontecendo cada vez mais em lugares onde vivem aqueles que eram, até pouco tempo, exclusivamente objetos favoritos da antropologia. Isso demanda a criação de novas estruturas de produção de conhecimento que [...] não submetam a diversidade cultural a um modelo que pretende ser único e eterno de forma exclusiva (2002, p. 399).

Muitas antropologias estão prontas a participar desse novo cenário. De fato, sua maior visibilidade internacional é um pré-requisito para termos uma comunidade mais heteroglóssica e igualitária de antropólogos mundiais e formas mais complexas de criar e circular teoria e conhecimento em nível global. Muito do aperfeiçoamento da antropologia dependerá de como respondermos a essa questão: em uma era de globalização intensa, e depois das fortes críticas epistemológicas e metodológicas dos últimos quinze anos, como podemos estabelecer novas condições de trocas acadêmicas e regimes de visibilidade?

\section{Poder e hegemonia na antropologia}

O debate sobre antropologias mundiais procura mostrar a existência de outros locais de produção de conhecimento sobre diversidade, tais como aqueles representados pela experiência da interculturalidad (Walsh, Schiwy e CastroGómez, 2002; De la Cadena, 2006). Também tem a intenção de criticar a troca desigual de informação e teoria existente internamente à antropologia. Tal desigualdade freqüentemente é discutida sob diferentes rótulos: antropologias centrais versus periféricas (Cardoso de Oliveira, 1999/2000); antropologias internacionais versus nacionais ou antropologias de construção da nação e antropologias de construção de império (Stocking, 1982); antropologias hegemônicas e não-hegemônicas (Ribeiro e Escobar, 2002); antropologias do Sul (Krotz, 1997); etc. Essas classificações são úteis para pensar as desigualdades existentes, mas precisamos transcender tais dualidades, já que, como diz Verena Stolcke (comunicação pessoal), não são capazes de lidar com ordens transnacionais. Elas também refletem vários tipos de relação de poder. De fato, a circulação internacional de idéias está altamente entrelaçada com relações de poder, e ela própria pode "ter o efeito de construir e reforçar a desigualdade" (L'Estoile, Neiburg e Sigaud, 2002, p. 23).

A antropologia tem uma longa relação com o poder estatal em todos os países onde é praticada e, em muitos aspectos, a disciplina foi modelada por essas relações. Onde há um regime autoritário, como nos tempos stalinistas na Rússia, a relação antropologia/Estado torna-se mais óbvia (Vakhtin, 2006). De um lado, elites estatais impõem um controle do potencial crítico da produção e da teoria antropológicas; de outro, convertem a antropologia em uma técnica de controle social, um tipo de engenharia social visando a administrar as relações entre minorias étnicas e poderosos governos centrais. Em tempos de guer$\mathrm{ra}$, como mencionamos anteriormente, mesmo em regimes não-autoritários, tais como o norteamericano, a antropologia pode ser chamada a desenvolver papéis similares além de se tornar uma fonte de inteligência sobre o inimigo. O papel da antropologia em processos de construção da nação é bem conhecido e não é preciso estender-se muito sobre ele. ${ }^{11}$ É suficiente dizer que antropólogos (re)criam ideologias contraditórias de unidade ou diversidade nacional, que são ancoradas na autoridade da produção acadêmica e freqüentemente se refletem em políticas de aparatos estatais (da educação e cultura ou da administração de conflitos étnicos) e em posições políticas de agentes da sociedade civil, como ONGs. Os dilemas que antropólogos australianos (Toussaint, 2006) estão enfrentando em disputas por terras aborígenes que chegam ao sistema judiciário nacional são um exemplo das formas intricadas de relações entre antropologia, aparato estatal e auto-representação da disciplina, principalmente no que diz respeito à autoridade de seu status científico vis-à-vis conflitos no interior do Estado-nação. Com efeito, a antropologia desenvolveu-se em relação aos interesses nacionais e internacionais sobre o status das populações nativas "encontradas" em territórios tradicionalmente controlados pelos Estados ou em novas áreas coloniais (L'Estoile, Neiburg e Sigaud, 2002).

É preciso pensar um pouco mais sobre as relações entre antropologia e construção de impé- 
rio, antropologia e colonialismo. Não obstante trabalhos como os de Asad (1973) e Stocking (1991), ainda necessitamos um estudo que detalhe cuidadosamente as complicadas relações entre a disciplina e as administrações coloniais (Ben-Ari, 1999). De um lado, a antropologia pode ter fornecido apoio a oponentes locais do poder colonial; de outro, Ben-Ari também argumenta que o conhecimento antropológico, junto com o censo, o mapa e o museu, eram parte do que Anderson (1991, p. 163) chamou de gramática do estilo colonial estatal de pensar sobre seu próprio domínio. Para Ben-Ari (Idem, p. 388), a questão crucial é entender o lugar da antropologia na construção de taxonomias e discursos coloniais. Na sua análise dos relacionamentos entre colonialismo francês e etnologia francesa, D'Estoile (2002) mostrou como várias pesquisas e instituições educacionais, tais como o Institute d'Ethnologie e o Musée de l'Homme, foram apoiados pelo aparato colonial francês, em um movimento contínuo de pessoas, informação e conhecimento entre "modos de conhecimento administrativo e discurso científico" com a intenção de legitimar a dominação racional sobre nativos africanos. ${ }^{12}$

Essa discussão também traz à tona os limites da antropologia como disciplina universal. A necessidade de separar os vínculos reais ou imaginados entre antropologia e colonialismo em países africanos ou asiáticos (Barnes, 1982; Kashoki, 1982) conduziu a uma crítica afiada por intelectuais pós-coloniais daquelas regiões. A África representa o melhor cenário para considerar a eficácia do discurso universalista antropológico, mais ainda do que a Índia. Na África, a pretensão universalista da antropologia logo foi relacionada ao eurocentrismo e desenvolveu um debate sobre a necessidade de uma epistemologia africana. Muito mais intensamente do que na Índia, onde o pensamento antropológico foi parte de debates pós-coloniais sobre construção da nação (Visvanathan, 2006), na África a disciplina foi pega entre o isolamento e o nativismo. De todo modo, qualquer pretensão a uma epistemologia nativista é um paradoxo já que, como Mafeje (2001) observou, d'aprés Rabinow, não há nada mais ocidental do que a discussão sobre epistemologia. Além disso, alegações de autenticidade cultural e científica podem bem ser um tipo de neo-orientalismo (Velho, 2006). Abordagens nativistas podem igualmente ser uma reação à existência de um corpo de intelectuais e literatura estrangeiros que mantêm os padrões válidos de interpretação sobre uma determinada cultura ou país. Velho argumenta que a ausência de brasilianistas, estudiosos estrangeiros do Brasil, contribuiu para impedir o desenvolvimento de uma abordagem nativista em nosso país.

A existência de uma antropologia - isto é, de uma disciplina que expandiu nos sistemas universitários durante o século XX - totalmente isolada de antropologias hegemônicas ocidentais é uma impossibilidade até em regimes autoritários (Vakhtin, 2006; Smart, 2006). A antropologia, desde seu começo, é uma cosmopolítica sobre alteridade de origem ocidental. Se o reconhecimento de uma determinada afirmação em antropologia depende da sua validade, esta validade, em última instância, depende de sua consagração por uma comunidade de argumentação que é também uma comunidade cosmopolita. Até perspectivas nativistas teriam que passar por esse tipo de processo. É por isso que é impossível acreditar em uma antropologia isolada, cuja validade seria inteiramente reconhecida e satisfeita apenas dentro dos limites do Estado-nação. Os exemplos da antropologia na Rússia e na China são, novamente, fortes indicadores de tal condição.

$O$ fato de a antropologia ter se expandido da região norte-atlântica para outros cantos do mundo não significa que não possa se beneficiar de suas muitas diferentes versões e das diferentes tensões que ela criou com sistemas locais préexistentes. Concordo com Shinji Yamashita quando argumenta que

[...] se a cultura viaja, como mostra James Clifford (1992), a antropologia também viaja. Através de sua viagem global, ela pode ser enriquecida e transformada por seus encontros com diferentes situações locais. Acredito firmemente que a antropologia do século XXI vai ser construída na base de relações "glocais", isto é "global-local" (Robertson, 1995), da mesma forma que outras grandes formas de produção cultural são construídas no mundo (1998, p. 5).

Mas é também verdade que há diferentes viajantes e formas de viajar. Hierarquias de 
conhecimentos e de cosmopolíticas são sempre baseadas em hierarquias de poder social e político. A situação indiana traz considerações interessantes. A maneira como a antropologia deslocou formas vernáculas de produção de conhecimento na Índia (Danda, 1995) não pode ser entendida sem considerar a geopolítica da língua, do conhecimento e do prestígio implementada pelo colonialismo britânico, que assegurou poder à língua, à cultura e à ciência do colonizador. $O$ inglês não foi universalmente ensinado na Índia colonial, mas apenas nos níveis mais elevados como a língua da administração, da ciência, da alta cultura e do sistema universitário (Hamel, 2003). Tal situação criou a necessidade de se identificar com a língua do colonizador, de desejá-la e praticá-la se certos agentes e agências quisessem ser vistos como parte da elite. A antropologia foi, desde o princípio, inserida e ensinada em um contexto maior que prefigurou seu próprio poder privilegiado sobre outras cosmopolíticas. Isso é certamente também o caso em países como o Peru, onde a subordinação do conhecimento indígena é a contrapartida da hegemonia das formações acadêmico-econômicas euro-norte-americanas, como afirma De la Cadena (2006). Em suma, se há algo que resta na discussão sobre antropologia nativa versus antropologia internacional/universal é que, no final, o insider é um cidadão, enquanto o outsider não. Estão em jogo os diferentes tipos de responsabilidade social e papéis políticos dos antropólogos. Outros problemas possivelmente associados são de ordem metodológica, sobretudo a respeito da natureza do encontro intersubjetivo na pesquisa de campo e do papel do estranhamento na construção do conhecimento antropológico.

\section{Construção de império e construção da nação}

Uma das dicotomias mais estabelecidas quando os antropólogos pensam a antropologia em escala global pode ser chamada de "dilema de Stocking”. De acordo com esse autor (1982), há antropologias de construção da nação e antropologias de construção de império. A eficácia desta formulação provém do fato de apontar para a amplitude do alcance do trabalho e da imaginação antropológicos, dependendo se os antropólogos fazem pesquisa de campo nos seus próprios países ou no exterior. A oposição antropologia tout court/antropologia em casa (uma expressão bastante popular nos Estados Unidos) indica que para as "antropologias imperiais" a disciplina significa pesquisa no exterior, e que fazer pesquisa em "casa" não é valorizado da mesma forma. Mas o dilema de Stocking pode ser superado se pensarmos que, nos tempos modernos, por trás da construção de um império há sempre um Estadonação. Com efeito, é bem conhecida a importância do colonialismo na criação e no reforço de ideologias nacionais nas metrópoles. De fato, antropologias de construção de império são também antropologias de construção de nação, mas o contrário não é verdadeiro. Além disso, tal dicotomia pode criar a impressão que há somente duas opções para as antropologias mundiais. Antropólogos em toda parte estariam restritos a servir à nação ou ao império, o que não é exatamente o caso. Primeiro, há antropologias de construção da diferença. Segundo, há "antropologias nacionais", tais como a australiana, brasileira, canadense e mexicana, que podem se tornar internacionais sem cair na tentação de virar antropologias de construção de impérios. O antropólogo português João de Pina Cabral, inspirado pela leitura de um livro sobre a antropologia brasileira, menciona a possibilidade de uma quinta tradição antropológica, diferente da norte-americana, da britânica, da francesa e da alemã, uma tradição "que não se sente identificada com qualquer dos projetos imperiais que, historicamente, moveram o desenvolvimento científico" (2004, p. 263). Archetti (2006) também mostrou que uma antropologia hegemônica, tal como a francesa, poder ser ao mesmo tempo voltada para a construção da nação e de um império. O exemplo japonês é também interessante, pois indica que uma antropologia pode ser nacional ou imperial ao longo do tempo (Askew, 2003), e, hoje, de fato, pósimperial. Atualmente, a pesquisa antropológica japonesa é bastante internacionalizada, mas não se relaciona com expansão imperial como foi o caso no passado.

O projeto de desenvolver cosmopolíticas acadêmicas pós-imperialistas na América Latina 
(Ribeiro, 2003) aponta para a existência de antropologias pós-nacionais e pós-imperiais, nas quais várias reversões de posições de poder são necessárias. Já que parte importante do projeto pósimperialista é provincializar os Estados Unidos por meio da crítica, por exemplo, das produções midiáticas e das matrizes ideológicas daquele país, uma das tarefas dos pesquisadores latinoamericanos seria gerar conhecimento mediante pesquisas de campo sobre questões norte-americanas, principalmente sobre aquelas que prefiguram poderosamente as cosmopolíticas e as ideologias de poder e prestígio. Ao mesmo tempo em que precisamos fazer pesquisa sobre os subalternos do Sul, é preciso fazer pesquisa sobre a elite do Norte. Para cima e para o Norte, vai o antropólogo. Já que hegemonia é a arte de exercer poder silenciosamente, vamos não apenas deixar os subalternos falarem, mas também fazer os poderosos falarem!

O vínculo entre antropologias e sistemas de poder é complexo, pois a antropologia, de muitas formas, faz parte de relações de poder e de constrangimentos muito mais amplos, incluindo os criados pelo desenvolvimento desigual em escala global. Há, por exemplo, sistemas educacionais, acadêmicos e científicos desenvolvidos diferentemente e com acessos distintos a recursos e poder do Estado-nação. Está claro, entretanto, que tais relações não podem ser reduzidas a uma disjunção entre antropologias de construção de império e antropologias de construção de nação. Os fatores subjacentes são os tipos de posições, perspectivas e práticas que os antropólogos têm a respeito de grupos e projetos poderosos e não-poderosos. Um modo de olhar esta questão é considerar que a antropologia é boa para prover a certos grupos, poderosos ou não, com conhecimentos que "legitimam" demandas sobre diversidade étnica e cultural e acesso a recursos naturais e sociais.

Antropologias mundiais pós-imperiais desenvolver-se-ão pela crítica teórica, mas também, e talvez de maneira mais importante, pela atividade política daqueles que se interessem em tais proposições. Antropologias mundiais implicam, por exemplo, na construção de outras condições de conversabilidade por intermédio da (re)união de antropólogos e de instituições antro- pológicas em redes para discutir como fazer com que forças heterogeneizantes da globalização trabalhem em favor de iniciativas heteroglóssicas. Esse é o motivo pelo qual Arturo Escobar e eu organizamos um simpósio internacional sobre Antropologias Mundiais, em março de 2003, na Itália, cujo resultado está publicado em World anthropologies: disciplinary transformations in systems of power (2006). É também o motivo pelo qual Paul Little e eu organizamos uma reunião no Brasil, em junho de 2004, que juntou a catorze presidentes de associações antropológicas nacionais e internacionais para discutir e negociar modos mais democráticos de interação global, produção e disseminação de conhecimento. ${ }^{13} \mathrm{~A}$ constatação, por todos, da importância da reunião e o seu entusiasmo demonstraram ser este o momento para criar modos mais horizontais $\mathrm{e}$ diversificados de interação e intercâmbio em nível global. Em conseqüência, o Conselho Mundial de Associações Antropológicas (World Council of Anthropological Associations) foi criado na reunião de Recife. O CMAA (WCAA) tem como objetivo principal promover intercâmbios mais diversos e equânimes entre antropologias e antropólogos em escala mundial. ${ }^{14}$

A crítica ao desequilíbrio de poder entre antropologias hegemônicas e não-hegemônicas é aqui realizada para irmos além da atual estrutura ossificada, para indicar que há muitas contribuições possíveis vindas de outras posições no sistema mundial e que se pode esperar uma fertilização cruzada mais complexa se formos capazes de construir outras condições de conversabilidade que promovam a criação de uma comunidade transnacional de antropólogos mais heteroglóssica. Em um artigo inspirado por vários debates, que ocorreram dentro do coletivo da Rede de Antropologias Mundiais, Eduardo Restrepo e Arturo Escobar escreveram que o projeto de "antropologias mundiais" é uma "intervenção direcionada à implosão dos constrangimentos disciplinares que modalidades subalternizadas da prática e imaginação antropológica têm que enfrentar em nome de um modelo normalizado e normalizante de antropologia" (2005, p. 100). Há duas noções que ajudam a entender a presente situação. Elas se referem ao que Dipesh Chakrabarty (2000, p. 28) 
chamou de ignorância assimétrica e eu chamo de tensão entre provincianismo metropolitano e cosmopolitismo provinciano.

\section{Provincianismos e cosmopolitismos invertidos}

Provincianismo metropolitano e cosmopolitismo provinciano são baseados nas relações desiguais existentes na economia simbólica global. Darei uma breve definição de ambas as noções. Provincianismo metropolitano significa a ignorância que centros hegemônicos geralmente têm da produção de centros não-hegemônicos. Cosmopolitismo provinciano significa o conhecimento que centros não-hegemônicos geralmente têm da produção de centros hegemônicos. Essa ignorância assimétrica pode se expressar em situações curiosas, embora comuns, como o fato de a história da antropologia universal (i.e. de antropologias hegemônicas) ser conhecida e estudada por antropólogos não-hegemônicos, mas o contrário não ser verdadeiro. Os processos pelos quais as antropologias sem história, para utilizar a expressão irônica e acertada de Krotz, tornaram-se institucionalizadas e cresceram não são ensinados ou, na melhor hipótese, são raramente ensinados até nos seus próprios países. Os clássicos incluem quase exclusivamente antropólogos estrangeiros.

Em muitos programas de pós-graduação fora do núcleo hegemônico, é obrigatória a capacidade de ler pelo menos duas línguas, além da nativa. De fato, o provincianismo metropolitano e o cosmopolitismo provinciano podem ser mais bem entendidos se considerarmos a questão da língua, sempre bastante complexa quando o que está em jogo é a comunicação transnacional. O inglês tem sido a língua mais expansiva nos últimos cinco séculos (Hamel, 2003, p. 16). Renato Ortiz (2004) mostra que o inglês mundial está estruturando os debates sociológicos em escala global. Ele também chega à conclusão de que existe uma relação entre a centralidade de uma língua no mercado mundial de bens lingüísticos e a proporção de traduções feitas para ela. É menor a proporção de textos traduzidos para as línguas mais centrais. Nos Estados Unidos e na Inglaterra, menos de 5\% das publicações são traduções, ao passo que na França e na Alemanha esse número é cerca de 12\%; na Espanha e na Itália, chega a 20\%. Tratase de um importante aspecto da base sociolingüística que sustenta o provincianismo metropolitano. Por extensão, pode-se dizer que o oposto é verdadeiro: quanto menos importante uma língua na economia simbólica global, mais traduções haverá para ela. Esta é uma das fontes sociolingüísticas do cosmopolitismo provinciano.

Rainer Enrique Hamel adverte que "o monolingüismo científico poderia não apenas aprofundar as desigualdades existentes no acesso e na difusão de descobertas científicas, mas também ameaçar a criatividade científica e a própria diversidade conceitual, bases do desenvolvimento científico" (2003, p. 24). Ele vê o perigo de passarmos de "uma forte hegemonia do inglês mundial para um monopólio; de um paradigma de diversidade poliglota, que admite conflito de línguas, para um paradigma monoglota, apenas do inglês" (Idem, p. 25). Se o monolingüismo científico levanta críticas tão amplas e sérias, uma antropologia mono-estilística pode ser considerada um impedimento para uma antropologia multicêntrica global.

A centralidade é um recurso positivo tanto quanto negativo quando lidamos com disciplinas que dependem de interpretação e contexto para aperfeiçoar suas capacidades heurísticas, como é o caso da antropologia. Ela é positiva porque nos grandes centros de produção há as melhores condições de trabalho (salários, bibliotecas, fundos de pesquisa, acesso à disseminação e visibilidade). É negativa ante a redução lingüística, cultural e política que trabalhar para um sistema universitário nacional específico implica (não importa quão grande e diverso seja, não se igualará à diversidade mundial) e por causa do provincianismo metropolitano, um fechamento lingüístico e sociológico que implica em grande perda de diversidade e de interesse em outras produções. Nesse sentido, se pensarmos na prática da antropologia em escala global, veremos uma enorme capacidade de fertilização cruzada, espalhada em diferentes "glocais", com um potencial de criatividade impossível de ser encontrado em um único lugar. Há evidências sociológicas e lingüísticas que tal criatividade está localizada em e vinda de 
locais não-hegemônicos, já que o cosmopolitismo provinciano permite uma visão mais diferenciada da disciplina como discurso internacional.

Não estou apelando para que se ignore as importantes contribuições que as antropologias hegemônicas fizeram e continuam fazendo para o conhecimento. Ao contrário, mencionei quão de perto a história e a produção da antropologia hegemônica são seguidas em todos os lugares. O que pretendo é deixar clara a necessidade de outras práticas acadêmicas que incluam trocas mais horizontais e que reconheçam a antropologia hoje como um discurso muito mais diverso do que as interpretações norte-atlanticêntricas supõem. Está na hora de lutar por multicentrismos em substituição a um ou poucos tipos de centrismos.

\section{Comentários finais}

Ben-Ari (1999, pp. 402-403), de forma instigante, refere-se à importância que criticar $\mathrm{O}$ envolvimento antropológico com o colonialismo tem para a carreira acadêmica de diferentes gerações de grupos acadêmicos. Será a noção de "antropologias mundiais" mais um capítulo da "política disciplinar" que se tornou possível por esse momento de globalização exacerbada? Ao mesmo tempo em que é válido afirmar que, como em qualquer outro campo, os antropólogos e outros estudiosos também estão em busca de poder, é igualmente necessário reconhecer que na nossa disciplina as críticas têm outros papéis além de serem uma parte da "política eleitoral" do mundo acadêmico (Trouillot, 1991). ${ }^{15}$ Críticas não deveriam ser vistas simplesmente como julgamentos desfavoráveis, mas como perquirições cuidadosas e posicionamentos fundamentais para $\mathrm{O}$ avanço de qualquer disciplina e para a constante melhoria das capacidades heurísticas e dos padrões éticos de seus praticantes. A proposta das "antropologias mundiais" não é uma demanda ressentida, um trampolim para ganhar autoridade sobre a antropologia hegemônica. A pretensão de uma perspectiva nativista foi claramente problematizada neste texto em favor de uma visão abertamente dialógica e heteroglóssica. Além disso, qualquer idéia de "periferia" como fonte essencial de autoridade, alteridade prístina ou de criatividade e radicalismo sem paralelos, está fadada a ser outro tipo de orientalismo (Velho, 2006). Se fossemos desenhar um mapa de interconexões e trocas atuais entre antropólogos, e fazer um catálogo de antropólogos mundiais, concordaríamos imediatamente com a visão de Johannes Fabian (2006), segundo a qual a antropologia tem, com sucesso, transnacionalizado muitos de seus praticantes, transformando-os em "cientistas" cuja estrutura mental não é mais determinada por identidades nacionais inquestionáveis.

Seria irônico se o projeto das antropologias mundiais fosse visto como a nova capacidade da "periferia" reagir, uma concepção simplista parecida com algumas interpretações sobre os objetivos das críticas pós-coloniais a respeito das antigas metrópoles imperiais. Prefiro pensar que esse é um momento de alargamento do horizonte antropológico que tornará a antropologia uma cosmopolítica acadêmica mais rica, capaz de lidar com os novos desafios que surgem no século XXI. Antropologias mundiais provêm uma janela de oportunidades para todos aqueles que sabem que a hegemonia de certo universalismo não é naturalmente dada; entendem que diferença não é desigualdade; e que a diversidade é um patrimônio da humanidade importante em qualquer atividade e prática humanas.

Neste texto, quis evitar uma abordagem intelectualista dos problemas que a teoria na antropologia tem enfrentado no passado e continua enfrentando hoje. Em vez disso, escolhi uma perspectiva sociológica a fim de sugerir que desafios e horizontes na teoria e na prática antropológicas estão embutidos em vários condicionamentos históricos. Meu objetivo foi mostrar que mudar as relações e os fluxos de informação internamente a uma comunidade global de antropologia ainda a ser plenamente desenvolvida é, hoje, uma forma poderosa de mudar orientações teóricas. Duas outras mudanças são igualmente necessárias: as que concernem a vínculos entre antropólogos e segmentos socioculturais diferenciados, e as relacionadas à pretensão da antropologia de ser o único discurso universalmente válido sobre alteridade.

Uma disciplina e seus praticantes são obviamente influenciados por contextos históricos, 
sociais, econômicos, políticos e culturais específicos. Por isso a transformação é uma constante na história da antropologia em qualquer lugar. De fato, a antropologia é uma fênix cuja morte, ou agonia prolongada, tem sido anunciada várias vezes, ao menos desde a década de 1920 quando Malinowski insistiu que os antropólogos fizessem mais trabalho de campo etnográfico, tendo em vista um mundo nativo que desaparecia. As muitas mortes e renascimentos da antropologia indicam sua habilidade de se transformar e direcionar sua crítica para si mesma, ampliando e redefinindo seus interesses, atribuições e teorias. A abundância de alternativas internamente à antropologia tornou-se um estímulo poderoso, levando a uma reavaliação do destino, do campo, dos objetivos, dos programas, das características e das definições da disciplina. As ressurreições e reencarnações da antropologia podem ser entendidas se considerarmos tratar-se de uma disciplina altamente reflexiva, que se projeta nos tópicos e nos assuntos que ela estuda e por eles é retroalimentada. Em conseqüência, a antropologia está em sintonia fina com as mudanças sociológicas que ocorrem historicamente. No mundo globalizado, precisamos ter vozes e perspectivas internacionais mais diversificadas participando em qualquer avaliação das fronteiras do conhecimento antropológico. Com efeito, o mundo globalizado é o cenário perfeito para a antropologia florescer, já que uma das lições básicas da disciplina é o respeito à diferença. Uma disciplina que elogia a pluralidade e a diversidade precisa promover tais dinâmicas em seu próprio meio. Este é o momento ideal para as antropologias mundiais.

\section{BIBLIOGRAFIA}

AHMAD, Aijaz. (1994), "Orientalism and after", in Patrick Williams e Laura Chrisman (orgs.), Colonial discourse and postcolonial theory, Nova York, Columbia University Press, pp. 162-171.

ALBERT, Bruce. (1995), "O ouro canibal e a queda do céu: uma crítica xamânica da economia política da natureza". Série Antropologia, 174, Brasília, Universidade de Brasília.
ANDERSON, Benedict. (1991), Imagined communities: reflections on the origins and spread of nationalism. Londres, Verso.

ARCHETTI, Eduardo P. (2006), "How many 'centers' and 'peripheries' in anthropology? A critical view on France", in Gustavo Lins Ribeiro e Arturo Escobar (orgs.), World anthropologies: disciplinary transformations in systems of power, Oxford, Berg Publishers.

ASAD, Talal. (1973), "Introduction", in Talal Asad (org.), Anthropology and the colonial encounter, Atlantic Highlands, Humanities Press, pp. 1-19.

ASKEW, David. (2003), "The debate on the 'Japanese' race in imperial Japan: displacement or coexistence?". Japanese Review of Cultural Anthropology, (3): 79-96.

BARNES, J. A. (1982), "Social science in India: colonial import, indigenous product, or universal truth?", in Husseim Fahim (org.), Indigenous anthropology in NonWestern countries, Durham, Carolina Academic Press, pp. 19-34.

BEN-ARI, Eyal. (1999), "Colonialism, anthropology and the politics of professionalization", in Jan van Bremen e Akitoshi Shimizu (orgs.), Anthropology and colonialism in Asia and Oceania, Hong Kong, Curzon, pp. 382-409.

BENEDICT, Ruth. (1946), The chrysanthemum and the sword. Boston, Houghton Mifflin.

CARDOSO DE OLIVEIRA, Roberto. (1999/2000), "Peripheral anthropologies 'versus' central anthropologies". Journal of Latin American Anthropology, 4 (2)-5 (1): 10-30.

CASTELLS, Manuel. (1996), The rise of the network society. Cambridge, Blackwell.

CHAKRABARTY, Dipesh. (2000), Provincializing Europe: postcolonial thought and historical difference. Princeton/Oxford, Princeton University Press.

CHEAH, Pheng \& ROBBINS, Bruce (orgs.). (1998), Cosmopolitics, thinking and fee- 
ling beyond the nation. Minneapolis, University of Minnesota Press.

CLIFFORD, James. (1992), "Traveling cultures", in L. Grossberg, C. Nelson e P. Treichler (orgs.), Cultural studies, Nova York/Londres, Routledge, pp. 96-116.

COPANS, Jean. (1974), Antropologia: ciência das sociedades primitivas? Lisboa, Edições 70.

(org.). (1975), Anthropologie et impérialisme. Paris, François Maspero.

DANDA, Ajit K. (1995), Foundations of anthropology: India. New Delhi, Inter-India Publications.

DE LA CADENA, Marisol. (2006), "The production of other knowledges and its tensions: from andeanist anthropology to interculturalidad?", in Gustavo Lins Ribeiro e Arturo Escobar (orgs.), World anthropologies: disciplinary transformations in systems of power, Oxford, Berg Publishers.

DIAMOND, Stanley. (1964), "A revolutionary discipline". Current Anthropology, 5: 432-437.

ESCOBAR, Arturo. (1995), Encountering development: the making and unmaking of the third world. Princeton, Princeton University Press.

FABIAN, Johannes. (2006), "World anthropologies': questions", in Gustavo Lins Ribeiro e Arturo Escobar (orgs.), World anthropologies: disciplinary transformations in systems of power, Oxford, Berg Publishers.

FAHIM, Husseim (org.). (1982), Indigenous anthropology in Non-Western countries. Durham, Carolina Academic Press.

GOLDMAN, Marcio \& NEIBURG, Federico. (2002), "Da nação ao império: a guerra e os estudos do "caráter nacional", in Benoît de L'Estoile, Federico Neiburg e Lygia Sigaud (orgs.), Antropologia, impérios e Estados nacionais, Rio de Janeiro, Relume Dumará/Faperj, pp. 187-217.

GOUGH, Kathleen. (1975), "Des propositions nouvelles pour les anthropologues", in Jean
Copans, Anthropologie et impérialisme, Paris, François Maspero, pp. 17-59.

HAMEL, Rainer Enrique. (2003), Language empires, linguistic imperialism and the future of global languages. México, Universidad Autónoma Metropolitana Unidad Iztapalapa (mimeo.).

HARVEY, David. (1989), The condition of postmodernity. Oxford, Basil Blackwell.

HYMES, Dell (org.). ([1969] 1974), Reinventing anthropology. Nova York, Vintage Books.

KASHOKI, Mubanga E. (1982), "Indigenous scholarship in African universities: the human factor", in Husseim Fahim (org.), Indigenous anthropology in NonWestern countries, Durham, Carolina Academic Press, pp. 35-51.

KROEBER, Alfred L. ([1953] 1970), "Introduction", in _______ (org.), Anthropology today, Chicago, University of Chicago Press, pp. xiii-xv.

KROTZ, Esteban. (1997), "Anthropologies of the South: their rising, their silencing, their characteristics". Critique of Anthropology, 17 (3): 237-251.

. (2002), La otredad cultural entre utopia y ciencia: un estúdio sobre el origen, el desarrollo y la reorientación de la antropología. México, Universidad Autónoma Metropolitana - Unidad Iztapalapa/ Fondo de Cultura Económica.

. (2006), "Mexican anthropology's ongoing search for identity", in Gustavo Lins Ribeiro e Arturo Escobar (orgs.), World anthropologies: disciplinary transformations in systems of power, Oxford, Berg Publishers.

L'ESTOILE, Benoît de. (2002), "Ciência do homem e 'dominação racional': saber etnológico e política indígena na África colonial francesa", in Benoît de L'Estoile, Federico Neiburg e Lygia Sigaud (orgs.), Antropologia, impérios e Estados nacionais. Rio de Janeiro, Relume Dumará/Faperj, pp. 61-93. 
L'ESTOILE, Benoît de; NEIBURG, Federico \& SIGAUD, Lygia. (2002), "Antropologia, impérios e Estados nacionais: uma abordagem comparativa", in (orgs.), Antropologia, impérios e Estados nacionais. Rio de Janeiro, Relume Dumará/Faperj, pp. 9-37.

LÉVI-STRAUSS, Claude. (1966), "Anthropology: its achievement and future". Current Anthropology, 7: 124-127.

LEWIS, Diane. (1973), "Anthropology and colonialism". Current Anthropology, 14 (5): 581-602.

LOMNITZ, Claudio. (2002), "A antropologia entre fronteiras: dialética de uma tradição nacional (México)", in Benoît de L'Estoile, Federico Neiburg e Lygia Sigaud (orgs.), Antropologia, impérios e Estados nacionais. Rio de Janeiro, Relume Dumará/Faperj, pp. 125-158.

MAFEJE, Archie. (2001), "Anthropology in postindependence Africa: end of an era and the problem of self-redefinition", in African social scientists reflections. Part 1, Nairobi, Heinrich Boll Foundation.

NKWI, Paul Nchoji. (2006), "Anthropology in a post-colonial Africa: the survival debate", in Gustavo Lins Ribeiro e Arturo Escobar (orgs.), World anthropologies: disciplinary transformations in systems of power, Oxford, Berg Publishers.

ORTIZ, Renato. (2004), "As ciências sociais e o inglês". Revista Brasileira de Ciências Sociais, 19 (54), fev.

PEIRANO, Mariza. (1991), "The anthropology of anthropology: the Brazilian case". Série Antropologia, 110, UnB.

PINA CABRAL, João de. (2004), "Uma história de sucesso: a antropologia brasileira vista de longe", in Wilson Trajano Filho e Gustavo Lins Ribeiro (orgs.), O campo da antropologia no Brasil, Rio de Janeiro/Brasília, Contracapa/ABA, pp. 249-265.

RAMOS, Alcida R. (2004), "'Our knowledge is our trademark' or disengaging ethnography". Universidade de Brasília (mimeo.)
RESTREPO, Eduardo \& ESCOBAR, Arturo. (2005), "Other anthropologies and anthropology otherwise: steps to a world anthropology network". Critique of Anthropology, 25 (2): 99-128.

RIBEIRO, Gustavo Lins. (1998), "Cybercultural politics: political activism at a distance in a transnational world", in Sonia Alvarez, Evelina Dagnino e Arturo Escobar (orgs.), Cultures of politics/politics of cultures: revisioning Latin American social movements, Boulder, Colorado, Westview Press, pp. 325-352.

(2003), Postimperialismo: cultura $y$ política en el mundo contemporáneo. Barcelona/Buenos Aires, Gedisa.

RIBEIRO, Gustavo Lins \& ESCOBAR, Arturo. (2002), "World anthropologies. disciplinary transformations within systems of power". Organizers' Statement. International Symposium of the WennerGren Foundation for Anthropological Research, Nova York, (mimeo.).

(orgs.). (2006), World anthropologies: disciplinary transformations within systems of power. Oxford, Berg Publishers.

ROBERTSON, Roland. (1995), "Glocalization: time-space and homogeneity/heterogeneity", in Mike Featherstone et al. (orgs.), Global modernities, Londres, Sage Publications, pp. 25-44.

SMART, Josie. (2006), "In search of anthropology in China", in Gustavo Lins Ribeiro e Arturo Escobar (orgs.), World anthropologies: disciplinary transformations in systems of power, Oxford, Berg Publishers.

SOUZA LIMA, Antonio. (2002), "Indigenismo no Brasil: migração e reapropriações de um saber administrativo", in Benoît de L'Estoile, Federico Neiburg e Lygia Sigaud (orgs.), Antropologia, impérios e Estados nacionais, Rio de Janeiro, Relume Dumará/Faperj, pp. 159-186.

STOCKING, George W. (1982), "Afterword: a view from the center”. Ethnos, 47 (1): 173-186. (1991), Colonial situations: essays on 
the contextualization of ethnographic knowledge. Madison, University of Wisconsin Press.

SUZUKI, Peter T. (1981), "Anthropologists in the wartime camps for Japanese-Americans: a documentary study". Dialectical Anthropology, 5 (1): 33-46.

TOUSSAINT, Sandy. (2006), "A time and place beyond and of the centre: Australian anthropologists in the process of becoming”, in Gustavo Lins Ribeiro e Arturo Escobar (orgs.), World anthropologies: disciplinary transformations in systems of power, Oxford, Berg Publishers.

TROUILLOT, Michel-Rolph. (1991), “Anthropology and the savage slot: the poetics and politics of otherness", in Richard Fox (org.), Recapturing anthropology: working in the present, Santa Fe, School of American Research Press, pp. 18-44.

TURNER, Terence. (1994), "Anthropology and multiculturalism: what is anthropology that multiculturalists should be mindful of it"?, in David Theo Goldberg (org.), Multiculturalism: a critical reader, Cambridge, Mass./Oxford, Blackwell, pp. 406-425.

VAKHTIN, Nikolai. (2006), "Transformations in Siberian anthropology", in Gustavo Lins Ribeiro e Arturo Escobar (orgs.), World anthropologies: disciplinary transformations in systems of power, Oxford, Berg Publishers.

VELHO, Otávio G. (1980), "Antropologia para sueco ver". Dados. Revista de Ciências Sociais, 23 (1): 19-91.

. (2006), "The pictographics of Tristesse: an anthropology of nation-building in the tropics and its aftermath", in Gustavo Lins Ribeiro e Arturo Escobar (orgs.), World anthropologies: disciplinary transformations in systems of power, Oxford, Berg Publishers.

VISVANATHAN, Shiv. (2006), "Official hegemony and contesting pluralisms", in Gustavo Lins Ribeiro e Arturo Escobar (orgs.),
World anthropologies: disciplinary transformations in systems of power, Oxford, Berg Publishers.

WALSH, Catherine; SCHIWY, Freya \& CASTROGÓMEZ, Santiago (orgs.), (2001), Indisciplinar las ciencias sociales - geopoliticas del conocimiento y colonialidad del poder: perspectivas desde lo andino. Quito, Universidad Andina Simón Bolívar/Ediciones Abya-Yala.

WEBER, Florence. (2002), "A ciência social em guerra: folclore, história e Estado na França (1937-1945)", in Benoît de L'Estoile, Federico Neiburg e Lygia Sigaud (orgs.), Antropologia, impérios e Estados nacionais, Rio de Janeiro, Relume Dumará/Faperj, pp. 219-234.

WERBNER, Pnina. (1997), "Introduction: the dialectics of cultural hybridity", in Pnina Werbner e Tariq Modood (orgs.), Debating cultural bybridity: multi-cultural identities and the politics of antiracism, Londres/New Jersey, Zed Books, pp. 1-26.

WOLF, Eric R. ([1969] 1974), "American anthropologists and American society", in Dell Hymes (org.), Reinventing anthropology, Nova York, Vintage Books, pp. 251-263.

WOLF, Eric R. \& JORGENSEN, Joseph G. (1975), "L'anthropologie sur le sentier de la guerre en Thailande", in Jean Copans (org.), Anthropologie et impérialisme, Paris, François Maspero, pp. 61-93.

YAMASHITA, Shinji. (1998), "Introduction: viewing anthropology from Japan". Japanese Review of Cultural Anthropology, (1): 3-6.

. (2006), "Reshaping anthropology: a view from Japan", in Gustavo Lins Ribeiro e Arturo Escobar (orgs.), World anthropologies: disciplinary transformations in systems of power. Oxford, Berg Publishers. 


\section{Notas}

* (continuação)

Beneficiei-me também de uma apresentação que fiz em um dos seminários do Departamento de Antropologia da Universidade da Carolina do Norte, em agosto de 2004. Em fevereiro de 2005, discuti esses temas com colegas da Sociedade Japonesa de Antropologia Cultural, em um seminário no Departamento de Antropologia da Universidade de Osaka. Em julho de 2005, estas idéias foram apresentadas como uma conferência no Primeiro Congresso Latino-americano de Antropologia, em Rosário, Argentina. O presente texto é, em grande medida, o resultado de um processo que também incluiu a organização, com Arturo Escobar, de um Simpósio Internacional patrocinado pela Fundação Wenner-Gren Para Pesquisa Antropológica, em Podernone, Itália, em março de 2003. Em Ribeiro e Escobar (2006) o leitor poderá encontrar os resultados do Simpósio Antropologias Mundiais: Transformações Disciplinares Internamente a Sistemas de Poder. Várias passagens aqui incluídas fazem parte da introdução daquele livro. Agradeço a Alcida Ramos, Eduardo Restrepo, Marisol de la Cadena e Susana Narotsky por seus comentários e sugestões, assim como a todos os colegas que deram parte do seu tempo para discutí-lo comigo. Erica Bernhardt colaborou com a tradução deste trabalho.

1 Inspirados por debates internos à RAM, Marisol de la Cadena e eu organizamos uma sessão na reunião de 2002 da Associação Americana de Antropologia - AAA. Paul Little e eu organizamos um encontro no Brasil de catorze presidentes de associações nacionais e internacionais de antropologia a fim de discutir formas de construir uma comunidade global mais plural de antropólogos. No encontro de Recife, em 2004, foi criado o Conselho Mundial de Associações Antropológicas. Sobre o Conselho, ver mais adiante.

2 Sobre cosmopolítica, ver Cheah e Robbins (1998), Ribeiro (2003).

3 Mas se bem é certo que a particularidade da antropologia se encontra na sua história de pensar alteridade e diversidade, ela não pode ser reduzida exclusivamente a isso. Para muitos antropólogos, noções como o "outro" e "alteridade" são problemáticas. Agradeço a Eduardo Restrepo por me relembrar essas questões.

4 Esteban Krotz (2002, p. 353) chama atenção para uma "certa predisposição" de autores que escre- vem sobre a história da antropologia, "determinados pela língua, história e cultura de seus países de origem. Por exemplo, o francês Claude Lévi-Strauss considera que a antropologia começou com Rousseau e Durkheim, enquanto a britânica Lucy Mair realça a importância de Adam Smith; em contrapartida, o alemão Wilhelm Muhlmann enfatiza o papel particular de Herder, e para o italiano Ernesto de Martino, Giambattista Vico é, naturalmente, de importância especial".

5 No começo da década de 1970, Jean Copans (1974, p. 52) constatou que "a história da etnografia é também a história das relações entre as sociedades européias e as sociedades não-européias". Ele antecipou que a descolonização teria um impacto na teoria e na prática da disciplina. Archie Mafeje (2001, p. 49) considerou que "a lição importante a ser tirada da experiência dos antropólogos africanos é que a antropologia tem como premissa uma relação imediata de sujeito/objeto. Se por razões sociais ou políticas essa relação for transformada, os antropólogos poderiam tornar-se incapazes de se autoconceberem se não redefinirem a si próprios e à sua disciplina”.

6 Antonio Carlos de Souza Lima (2002) mostra como o indigenismo mexicano migrou para outros países da América Latina, principalmente para o Brasil.

7 Sobre a relação entre o colonialismo francês e a antropologia, ver L'Estoile (2002).

8 Para alguns dos dilemas da etnologia francesa no governo Vichy, ver Weber (2002).

9 No encontro da AAA de 1966, uma moção contra o papel do governo norte-americano no Vietnam causou grande controvérsia; para uma outra indicação de quão ideologicamente divididos estavam os antropólogos norte-americanos, ver Gough (1975).

10 Ben-Ari (1999, p. 400) afirma que a literatura de angústia é "agora tida como tão importante para compreender a sociologia do conhecimento quanto as questões mais convencionais de metodologia, estudo da língua ou de como ingressar e obter bons relacionamentos no campo".

11 Para o caso brasileiro, ver, por exemplo, Peirano (1991).

12 "Na situação colonial, o estudo científico de nativos aparece, junto com ações nas áreas de educação e saúde, como um meio privilegiado para demonstrar simultaneamente a 'humanidade profunda' (a preocupação com as populações indígenas e seus costumes) e a superioridade científica do poder tutelar" (L'Estoile, 2002, pp. 75-76). A superioridade 
científica seria um meio pacífico e convincente de mostrar a legitimidade do empreendimento colonial, algo que na França ganhou vida própria em uma Escola Colonial, sustentada pelo governo na primeira metade do século XX, para treinar administradores mediante uma educação especializada que poderia dar à colonização "um espírito científico de boa qualidade" (Idem, p. 77).

13 Em ambas as iniciativas, contamos com o apoio da Fundação Wenner-Gren para a Pesquisa Antropológica (Nova York). Os presidentes das associações dos seguintes países estiveram presentes na reunião em Recife: Austrália, Brasil, Canadá, França, Índia, Grã-Bretanha, África do Sul e Estados Unidos. O Japão mandou o diretor de relações internacionais da sua associação. Os presidentes das seguintes associações internacionais também lá estiveram: Associação Européia de Antropólogos Sociais, Associação Latino-Americana de Antropologia, Associação Antropológica PanAfricana e União Internacional das Ciências Antropológicas e Etnológicas.

14 A esse respeito, ver site www.wcaanet.org.

15 Políticas eleitorais são "uma série de práticas institucionalizadas e relações de poder que influenciam a produção de conhecimento dentro da academia: filiações acadêmicas, mecanismos de institucionalização, organização de poder dentro dos e entre os departamentos, valor atribuído às publicações obrigatórias, e outros temas mundanos que incluem as manobras às quais normalmente nos referimos como 'política acadêmica', mas vão bem além delas" (Trouillot, 1991, p. 143). 


\section{ANTROPOLOGIAS MUNDIAIS: PARA UM NOVO CENÁRIO GLOBAL NA ANTROPOLOGIA}

\section{Gustavo Lins Ribeiro}

Palavras-chave: Conhecimento e hegemonia; Globalização acadêmica; Cosmopolítica; Transnacionalismo.

Em uma época de globalização exacerbada, os antropólogos não têm discutido consistentemente a natureza corrente de sua prática e das transformações que ela atravessa em escala global. Este artigo considera a antropologia uma cosmopolítica que se consolidou como disciplina acadêmica formal no século XX, internamente a um sistema universitário ocidental em crescimento e em expansão. Insere-se no campo de uma antropologia crítica da antropologia, que descentra, re-historiciza e pluraliza o que se entende como antropologia até o momento. O autor questiona não apenas os conteúdos, mas também os termos e as condições das conversações antropológicas. Enfoca, ainda, questões relativas ao enredamento da antropologia com geopolítica e poder nacional/global. Além disso, enfatiza que o papel cada vez maior das antropologias não-hegemônicas na produção e na disseminação de conhecimento em escala global revela uma nova força transformadora interna à própria antropologia.

\section{WORLD ANTHROPOLOGIES: TOWARDS A NEW GLOBAL SCE- NARIO IN ANTHROPOLOGY}

Gustavo Lins Ribeiro

Keywords: Knowledge and hegemony; Academic globalization; Cosmopolitics; Transnationalism.

In an age of heightened globalization, anthropologists have failed to discuss consistently the current nature of their practice and its transformations on a global scale. This article views anthropology as a cosmopolitics that consolidated itself as a formal academic discipline in the $20^{\text {th }}$ century within a growing Western university system that expanded throughout the world. It is part of a critical anthropology of anthropology, one that decenters, re-historicizes, and pluralizes what has been taken as "anthropology" so far. It questions not only the contents but also the terms and the conditions of anthropological conversations. It also focuses on issues that reveal how anthropology got entangled with geopolitics and national/global power. The article emphasizes that the increasingly important role non-hegemonic anthropologies play in the production and dissemination of knowledge on a global scale is a new transformative force coming from within anthropology itself.
ANTHROPOLOGIES MONDIALES : POUR UN NOUVEAU SCÉNARIO GLOBAL DANS L'ANTHROPOLOGIE

Gustavo Lins Ribeiro

Mots-clés: Savoir et hégémonie; Globalisation académique; Cosmopolitique; Transnationalisme.

Dans une ère de globalisation exacerbée, les anthropologues n'abordent pas, de façon consistante, la discussion à propos de la nature courante de sa pratique et des transformations qu'elle traverse à l'échelle globale. Cet article considère l'anthropologie en tant que cosmopolitique consolidée comme discipline académique formelle au $\mathrm{XX}^{\mathrm{e}}$ siècle, dans le cadre d'un système universitaire occidental en pleine croissance et en expansion. Elle s'insère dans le champs d'une anthropologie critique de l'anthropologie, qui décentre, replace dans son contexte historique et diversifié ce que l'on a considéré, jusqu'à présent, comme étant l'anthropologie. L'auteur questionne non seulement les contenus, mais aussi les termes et conditions des conversations anthropologiques. Il aborde, également, les questions relatives à l'anthropologie placée dans le réseau géopolitique et de pouvoir national et global. Il met aussi l'accent sur le fait que le rôle croissant des anthropologies non hégémoniques liées à la production et à la dissémination du savoir dans une sphère globale révèlent une nouvelle force transformatrice interne à la propre anthropologie. 